RUIDÍAZ GARCÍA, C., «La política social de atención a las personas dependientes en España. Balance y perspectivas de la Ley de dependencia», REDUR Io, diciembre 20I2, págs. I7I-I9I. ISSN I695-078X

\title{
LA POLÍTICA SOCIAL DE ATENCIÓN A LAS PERSONAS DEPENDIENTES EN ESPAÑA. BALANCE Y PERSPECTIVAS DE LA LEY DE DEPENDENCIA*
}

\author{
Carmen RUIDÍAZ GARCÍA \\ Profesora Titular de Trabajo Social \\ UNIVERSIDAD DE LA RIOJA
}

SumArio: Introducción. I. El cuidado: qué es el cuidado, quién necesita cuidado, quién cuida, políticas del cuidado, hacia un mayor cuidado público. II. La articulación del cuidado de personas dependientes en la Ley 39 /2006, de I4 de diciembre, de Promoción de la Autonomía Personal y atención a las personas en situación de dependencia. II.r. El cuidado como derecho social reconocido en la Ley 39 /2006, de I4 de diciembre, de Promoción de la Autonomía Personal y atención a las personas en situación de dependencia. II.2. Breve descripción del Sistema para la Autonomía y Atención a la Dependencia (SAAD). II.3. El modelo español de atención a la dependencia en perspectiva comparada. III. Luces y sombras en la implementación del sistema nacional de atención a la dependencia (SAAD). IV. A modo de balance. Bibliografía.

RESUMEN: Con este artículo se pretende analizar, de manera tentativa, la política social de atención a las personas dependientes que se vio fortalecida con la aprobación de la Ley 39/2006, de I4 de diciembre, de Promoción de la Autonomía Personal y atención a las personas en situación de dependencia. El corto espacio temporal desde la promulgación de la Ley de dependencia, la articulación del sistema de atención a las personas dependientes (SAAD) y el momento actual permite visualizar claros y oscuros sobre su desarrollo, consolidación y posibilidades de desarrollo futuro.

Palabras Clave: cuidado, políticas del cuidado, derechos sociales, dependencia.

ABSTRACT: This article analyzes, tentatively, social care policy for dependents that was strengthened with the passage of Law 39 /2006, of I4 December, on the Promotion of Personal Autonomy and Individual Care in situations of dependency. The short temporary space from the promulgation of the Law of dependence, the joint of the system of attention to the dependent persons (SAAD) and the current moment allows to visualize clear and dark on his development.

KEYWORDS: care, care policies, social rights, dependency.

\footnotetext{
* La base de este artículo se encuentra la comunicación presentada en el IV Congreso Internacional de Historia de nuestro tiempo. España en democracia, Logroño (La Rioja) 8 a Io de noviembre de 20I2, CUARTA SESIÓN. LA SEGUNDA ETAPA SOCIALISTA. EL SEPTENIO ZAPATERO, titulada «La atención a las personas dependientes: una ambiciosa política social del Gobierno socialista de José Luis Rodríguez Zapatero».
} 


\section{Introducción}

En los años de vigencia de la de la Ley 39 /2006, de I4 de diciembre, de Promoción de la Autonomía Personal y atención a las personas en situación de dependencia ${ }^{\mathrm{I}}$, son muchas las investigaciones, libros, artículos que se han escrito sobre el contexto jurídico, político y social que le vio nacer, el desarrollo normativo, la medida (cuantitativa y cualitativa) de su aplicación práctica (CASADO (2004), CASADO Y FANTOVA (2007), CHARRO Y SEMPERE (2008), CERVERA (2009), ARRIBA Y MORENO (2009)). Igualmente han proliferado un sinfín de reuniones científicas y profesionales, congresos, etc. que han ayudado a la mejor comprensión del alcance de este texto legal que ha penetrado en el tejido social de los hogares españoles y en las estructuras del Sistema público servicios sociales.

Este caudal de conocimientos teóricos y prácticos es en sí mismo una fuente de inspiración para seguir mirando y evaluando algunos aspectos de una Ley que a pocos ha dejado indiferentes.

El propósito de este artículo consiste en revisar algunas de las múltiples miradas que han estado presentes en la génesis y desarrollo de la política social del cuidado a las personas dependientes. Para ello, vamos a realizar un recorrido, a modo de contextualización, por el concepto y el contenido del cuidado (qué es el cuidado, quién necesita cuidado, quién cuida, políticas del cuidado). Seguidamente revisaremos como se ha ido articulando la atención a las personas en la Ley 39 /2006, de I4 de diciembre, de Promoción de la Autonomía Personal y atención a las personas en situación de dependencia, un texto legal en el que se reconoce por primera vez en nuestro ordenamiento jurídico el derecho social de las personas dependientes a ser atendidas, sin distinción de clase social, edad, sexo, étnica, etc. por los poderes públicos; una apuesta política que sitúa a España en una línea de partida similar a la de otros regímenes de bienestar europeos. Continuaremos el viaje presentando el desarrollo del marco normativo que sustenta el Sistema para la Autonomía Personal y Atención a la Dependencia (SAAD) y examinaremos algunos puntos polémicos, y otros no tan polémicos, relativos a la organización del sistema, prestaciones recogidas en el SAAD, mecanismos de financiación, entre otros. Terminaremos nuestro recorrido perfilando algunas luces y sombras que planean en la actualidad en torno a esta política social de atención a las personas en situación de dependencia.

I. El cuidado: qué es el cuidado, quién necesita cuidado, quién cuida, políticas del cuidado, hacia un mayor cuidado público ${ }^{2}$

Al reflexionar sobre el cuidado, Constanza Tobío (2008) provoca al lector obligándole a pensar en una escena, de fuerte carga dramática, de la película, La balada del Narayana ${ }^{3}$.

En esta escena se relata como en tiempo lejanos se acompañaba a las personas mayores a lugares aislados y se les dejaba allí para morir de inanición, cansancio, frio, etc.

\footnotetext{
${ }^{\text {I }}$ Ley 39 /2006, de I4 de diciembre, de Promoción de la Autonomía Personal y atención a las personas en situación de dependencia, conocida por Ley de dependencia o por el acrónimo LAPAD (fecha de disposición: I4 /I2/ 2006; fecha de publicación, I5/I2/2006, BOE n ${ }^{\circ}$ 299; entrada en vigor el I de enero de 2007).

${ }^{2}$ Para profundizar en este debate sobre el cuidado es recomendable consultar el texto de TOBÍO, C., AGULLO, M ${ }^{a}$ S., GÓMEZ, V. Y MARTÍN PALOMO, M ${ }^{a}$ T. El cuidado de las personas. Un reto para el siglo XXI. Obra Social «la Caixa», Colección Estudios Sociales, volumen 28, Barcelona, 2010 y también el artículo de TOBÍO, C. «Redes familiares, género y política social en España y en Francia». Política y Sociedad, vol. 45, 2008, núm. 2, pág. 87-I04.

${ }^{3}$ Largometraje de producción japonesa, Director Shohei Inamura, ganadora de la Palma de oro en I983.
} 
El dramatismo alcanza su punto álgido cuando, siguiendo la tradición, el hijo deja a su anciano padre, tal como lo hiciera antes el padre de su padre, en un bosque. El hijo emprende el camino de vuelta sin el padre, de repente mira hacia atrás, gira sobre sí mismo, recoge a su padre y se lo lleva de vuelta transgrediendo con este acto la ley consuetudinaria de la comunidad.

El cuento popular no dice qué ocurre después si el padre vive con el hijo, si es cuidado por el hijo, si el hijo abandona de nuevo al padre por la presión de la comunidad, si son las instituciones del poblado las que se hacen cargo del anciano, sin embargo las imágenes provocan e inquieta saber cómo se resuelve este dilema en la tradición japonesa ${ }^{4}$ y por extensión en otros contextos culturales.

Huelga decir que en la España de principios del XXI, con un Estado de bienestar bastante sólido, estamos lejos de este patrón de la cultura japonesa, es decir, a nadie (salvo casos extremos susceptibles de ser perseguidos de oficio) se le ocurriría dejar a sus padres en un bosque (o algo similar) y en el más absoluto aislamiento social.

Pero vayamos por partes e intentemos perfilar el universo del discurso revisando, en primer lugar, el propio concepto de cuidado.

Según el Diccionario de María Moliner, cuidar tiene múltiples connotaciones. La que más se aproxima a nuestros marco de análisis conlleva «Dedicar atención e interés a una cosa ... Atender a que una cosa esté bien o no sufra daño ... Atender a que ocurra o se haga»; por su parte, el cuidado significa tanto «Intranquilidad o preocupación por el temor de que haya ocurrido u ocurra algo malo» como «Acción de cuidar», cuidarse, en su forma reflexiva, «Necesita cuidarse ... Cuidar ... atender».

En los humanos, la primera forma del cuidado corresponde a los primeros años de vida ${ }^{5}$, años en los que todos, sin excepción, somos vulnerables, hasta el extremo de que no sobreviviríamos sin la atención externa continua. Los años finales se caracterizan también por la necesidad, creciente, de ser cuidados, aunque con intensidad muy variable. Entre estos dos extremos, se encuentran aquellos que, siendo una minoría, terminan su recorrido vital con buena salud y, en cambio, otros que, sin ser mayores, padecen alguna enfermedad o discapacidad que les limita su capacidad para desenvolverse sin ayuda de los demás.

Por lo demás, el cuidado es complejo y variado, con un espectro de posibilidades que van desde el autocuidado (cuidado que uno mismo se administra y que es clave para nuestro bienestar, el cuidado de sí mismo, consciente y reflexivo, es una condición para la disponibilidad hacia los demás, pero también expresión de la auténtica autonomía) hasta el cuidado que uno da de forma voluntaria, altruista, etc. y el cuidado que alguien recibe y, por último, el cuidado que se da por parte de las instituciones y organizaciones sociales (familia, ONGs, empresas o el propio Estado) y el que recibe el cuidado. En el ámbito de la

\footnotetext{
${ }^{4}$ En este caso, para comprender y entender algunos de los patrones culturales japoneses, es recomendable leer el libro de BENEDICT, R. El crisantemo y la espada: patrones de la cultura japonesa, reeditado recientemente por Alianza Editorial, 20II.

${ }^{5}$ René A. Spitz en su libro El primer año de vida del niño da cuenta del intercambio emocional y vivencial entre madre e hijo. Reflexiona acerca de la forma en que esta relación, desde sus inicios, garantiza la supervivencia del infante y el desarrollo somático y psíquico de su personalidad. La principal cuestión planteada, es el desarrollo de esta relación tan fundamental para el ser humano. El niño, durante el primer año de vida se esfuerza en sobrevivir y en elaborar formas de adaptación al medio. Todo aquello de lo que carece de pequeño, lo proporciona la madre quien atiende de manera complementaria todas sus necesidades, y el resultado de este cuidado y esta relación es una diada, principal herramienta para la supervivencia y la adaptación al medio.

En el libro también se encuentran reflexiones y datos interesantes sobre los efectos del internamiento en el desarrollo de los niños institucionalizados, privados de la atención materna.
} 
dependencia, todas estas variantes persiguen un mismo fin: proporcionar bienestar a las personas que necesitan cuidado.

Pero, quién necesita cuidado, es decir, quienes son las personas que padecen alguna enfermedad o discapacidad que les limita su capacidad para desenvolverse autónomamente. La respuesta no es simple, dado que no existe un solo nivel de enfermedad o de discapacidad. Todo es una cuestión de grado. ${ }^{6}$

Otro rasgo fundamental en la cadena del cuidado es el de la figura del cuidador: quién cuida al que necesita cuidado, cuáles son las características del cuidador.

En nuestra sociedad, los cuidadores se han diversificado en una variedad tipológica en la que intervienen factores como el parentesco, el género o la relación salarial.

Con carácter general, cuidan las madres y, cada vez más, los padres de sus hijos; las abuelas y abuelos de sus nietos; cónyuges de cónyuges; hijos adultos de progenitores mayores (en estas relaciones cuidan más ellas que ellos); amigos de amigos; también cuidan aquellos que lo hacen por una remuneración económica tanto en el ámbito privado de la familia como en el ámbito público, es decir, en las instituciones (privadas, públicas o mixtas) prestadoras de servicios de bienestar y, por último, los que lo hacen con carácter voluntario.

Cuidar es un esfuerzo físico y mental que genera a su vez necesidades específicas de cuidado. Cuidar a los cuidadores es un buen indicador de la sensibilidad social y del grado de desarrollo alcanzado en una sociedad en esta materia. ${ }^{7}$

El último eslabón de la cadena del cuidado nos lleva a considerar las políticas del cuidado, es decir, las respuestas políticas e institucionales que históricamente, y sobre todo en el momento actual, son las proveedoras del bienestar de las personas que necesitan cuidado.

La historia de la acción social da cuenta de las distintas formas y fórmulas de atención a las personas que necesitan ayuda ${ }^{8}$. Lo característico de nuestro tiempo histórico

\footnotetext{
${ }^{6}$ Un ejemplo extremo de dependencia se puede visualizar en la película española ganadora de un Óscar en 2004, dirigida por Alejandro Amenábar, Mar adentro.

La película encuentra su inspiración en la historia real de Ramón Sampedro, marinero, que tras un accidente en su juventud queda tetrapléjico y permanece postrado en una cama durante cerca de 30 años. El marinero desea morir dignamente pero en su vida están presentes personas que, unas veces a favor o en contra de su deseo de morir, dibujaran un panorama tenso y complejo. Su mundo es su habitación y a ella llegan Julia, su abogada (que padece CADASIL), y Rosa, una vecina que intenta por todos los medios a su alcance convencerle de que la vida merece la pena ser vivida. Pero, la fortaleza de Ramón, su energía vital, llevan a cambia por completo los principios de las dos mujeres.

Este film, ayuda a contextualizar el fenómeno de la dependencia y también anima a pensar sobre la figura del cuidador.

También cabe citar como ejemplo el film Intocable (20II), dirigido por Olivier Nakache, Eric Toledano. «Philippe, un aristócrata que se ha quedado tetrapléjico a causa de un accidente de parapente, contrata como cuidador a domicilio a Driss, un inmigrante de un barrio marginal recién salido de la cárcel. Aunque, a primera vista, no parece la persona más indicada, los dos acaban logrando que convivan Vivaldi y Earth Wind and Fire, la elocuencia y la hilaridad, los trajes de etiqueta y el chándal. Dos mundos enfrentados que, poco a poco, congenian hasta forjar una amistad tan disparatada, divertida y sólida como inesperada, una relación única en su especie de la que saltan chispas». Fuente: http://www.filmaffinity.com/es/film2I77ıı.html.

7 Por ejemplo, tomando en consideración la variable, quién da como persona física proveedora de bienestar, en la relación personal de que necesita cuidado y el que lo da se configuran distintas situaciones y vínculos entre ellos (aceptación mutua, rechazo, compenetración, proteccionismo; qué tipo de relación contractual existe en esta relación (voluntaria, trabajo remunerado), cómo repercute la acción del cuidador en la calidad de vida del cuidado, etc.).
} 
en la implicación de los poderes públicos en el cuidado de las personas. Es decir, en nuestras sociedades complejas (modernas, postmodernas, postindustriales, del conocimiento, del riesgo o cualquier otro vocablo que se les quiera atribuir), cuidar a las personas forma parte de las políticas públicas de los Estados de bienestar, más en esta tarea el Estado no está solo, el cuidado es una actuación de múltiples instituciones y organizaciones de la sociedad civil, de la familia, de los amigos, etc.

Este nuevo panorama no es casual. En nuestro contexto cultural, el siglo XX, y también el XXI, es el siglo de la ampliación de derechos sociales de los individuos donde el Estado se transforma progresivamente en protector ante los riesgos y contingencias que experimentan las personas a lo largo de la vida.

Este escenario ha cambiado las reglas del juego y ha obligado a diseñar nuevas políticas sociales que han ampliado los pilares clásicos del Estado de bienestar (sanidad, pensiones y educación): el cuidado de menores, mayores y personas dependientes no es una excepción que se da cuando no hay familia o amigos que puedan asumirlo, sino que es un derecho social que tiene y debe ser respaldado por un marco legal y un sistema que lo soporte.

El cuidado es una cuestión de política social que levanta pasiones éticas y políticas. La opinión pública tiende a oscilar entre dos posturas extremas: una centrada en la responsabilidad de los individuos y las familias en su propio bienestar, y otra que espera que la sociedad en su conjunto asuma la responsabilidad en, al menos, algunos aspectos de la asistencia. ${ }^{9}$

Por lo que concierne a nuestro país, el impulso de la política social del cuidado (cuidado social), lo que podemos denominar como nuevos derechos sociales que incluyen todos aquellos relacionados con el cuidado de las personas, se formula como tal en un contexto de cambio familiar, crisis del Estado de bienestar, crisis de valores y, en los últimos años, profunda crisis económica.

\footnotetext{
${ }^{8}$ El cuidado de mayores y dependientes hunde sus raíces en las prácticas de las leyes de pobres surgidas durante el periodo de la industrialización. Las administraciones locales eran originariamente responsables de las medidas de alivio de la pobreza; por ejemplo, tenían que disponer de alojamiento para quienes no eran atendidos por sus familiares, amigos, patronos, etc. Las instituciones residenciales demostraron ser un medio importante para dar respuesta a las necesidades de estos grupos de población. Los sistemas de atención de la pobreza administrados localmente experimentaron un proceso de diferenciación a lo largo del siglo XIX, con la creación de diferentes categorías de pobres: los niños, los delincuentes, los discapacitados, etc. y fueron remitidos a instituciones separadas, algunas, como es el caso de los mayores, se convirtieron en el embrión de lo que hoy conocemos como residencias de mayores.

Más el paso del tiempo ha dejado su huella y cabe apreciar grandes diferencias en la evolución de las políticas públicas desde las antiguas leyes de pobres a los servicios modernos de cuidado social (entendiendo por cuidado social las políticas públicas de cuidado en contraposición al cuidado informal o cuidado en el hogar).

${ }^{9}$ Dicho de otro modo, la aceptación de la idea de que la responsabilidad del cuidado de las personas dependientes pueda incumbir a otras personas que no sean los miembros de la propia familia, y en particular las mujeres que la integran, se desarrolla con bastante lentitud. En ocasiones, la provisión de un servicio público y el cuidado familiar se contemplan como opciones alternativas, incluso enfrentadas. Se piensa incluso que, a medida que el Estado y sus instituciones formales amplíen su intervención, las familias se retirarán delegando parte de sus responsabilidades familiares. En esta línea discursiva se encuentran los que consideran que la provisión del cuidado por parte de las políticas públicas conlleva un riesgo ético importante para la sociedad.
} 


\section{La articulación del cuidado de personas dependientes en la Ley $39 / 2006$, de I4 de diciembre, de Promoción de la Autonomía Personal y atención a las personas en situación de dependencia ${ }^{\text {IO }}$}

En España, la protección de personas dependientes tradicionalmente se ha caracterizado, por un lado, por estar relegada al ámbito privado y, por otro, por ser considerada como insuficiente. Sin embargo, la Ley 39 /2006, de I4 de diciembre, de Promoción de la Autonomía Personal y atención a las personas en situación de dependencia marcó un punto de inflexión en el universo del cuidado institucional, en la medida en que el viejo modelo contributivo y asistencial, orientado a las personas con carencia de recursos, da paso a formas de acción universalistas dirigidas en el terreno del derecho social a la autonomía de las personas y a apoyar las situaciones de dependencia.

Este nuevo sistema protector tiene como objetivo un riesgo que tradicionalmente se consideraba un asunto privado, casi exclusivo de las familias y, en el círculo familiar, generalmente resuelto por las mujeres. De modo que, por primera vez en España, se reconoce el derecho individual a la autonomía de las personas con limitaciones funcionales y el derecho al cuidado, como un derecho de ciudadanía. ${ }^{\text {II }}$ Pero hagamos un poco de historia.

Autores como Rodríguez Cabrero, G. (20II) ${ }^{\mathrm{I2}}$ apuntan que la Ley de dependencia es fruto de un largo debate político y científico iniciado con el Plan Gerontológico Estatal de

\footnotetext{
${ }^{\text {Io }}$ La LAPAD se estructura en un título preliminar; un título primero con cinco capítulos; un título segundo con cinco capítulos; un título tercero; dieciséis disposiciones adicionales; dos disposiciones transitorias y nueve disposiciones finales. En el título preliminar se recoge las disposiciones que se refieren al objeto de la Ley y los principios que la inspiran, los derechos y obligaciones de las personas en situación de dependencia, y los titulares de esos derechos. El título I configura el Sistema de Atención a la Dependencia, la colaboración y participación de todas las Administraciones Públicas en el ejercicio de sus competencias, a través de los diversos niveles de protección en que administrativamente se organizan las prestaciones y servicios. La necesaria cooperación entre Administraciones se concreta en la creación de un Consejo Territorial del Sistema, en el que podrán participar las Corporaciones Locales y la aprobación de un marco de cooperación interadministrativa a desarrollar mediante Convenios con cada una de las Comunidades Autónomas. Asimismo, se regulan las prestaciones del Sistema y el catálogo de servicios, los grados de dependencia, los criterios básicos para su valoración, así como el procedimiento de reconocimiento del derecho a las prestaciones. El título II regula las medidas para asegurar la calidad y la eficacia del Sistema, con elaboración de planes de calidad y sistemas de evaluación, y con especial atención a la formación y cualificación de profesionales y cuidadores. En este mismo título se regula el sistema de información de la dependencia, el Comité Consultivo del sistema en el que participarán los agentes sociales y se dota del carácter de órganos consultivos a los ya creados, Consejo Estatal de Personas Mayores y del Consejo Nacional de la Discapacidad y Consejo Estatal de Organizaciones no Gubernamentales de Acción Social. Por último, se regulan en el título III las normas sobre infracciones y sanciones vinculadas a las condiciones básicas de garantía de los derechos de los ciudadanos en situación de dependencia.
}

${ }^{\text {II }}$ La LAPAD ha marcado el camino para pasar de un modelo asistencialista a uno de bienestar. La aprobación de la Ley de dependencia ha supuesto la superación de un modelo cuyas acciones de protección daban cuenta mayormente de la «asistencia social» (actividades administrativas encaminadas a auxiliar, con cargo a fondos generales del Estado, a aquellas personas que no se encuentran en condiciones económicas para atender, por sí, necesidades consideradas básicas) y que se proveían por vía de la Seguridad Social en lo relativo a las prestaciones económicas o por vía de los Servicios Sociales en lo concerniente a los servicios, a un modelo de carácter universal que supone asumir algunas de las ventajas de los modelos con más experiencia histórica de los sistemas de bienestar europeos (especialmente el continental y el nórdico centrados en el carácter universal, el sistema de copago, la responsabilidad pública, la preferencia de servicios y la orientación a dignificar la figura del cuidador /a).

Ahora bien, el modelo universalista no está exento de problemas y limitaciones, por ejemplo, problemas de universalización real, es decir, de accesibilidad a los servicios, de calidad, de coordinación entre sistemas e instituciones o de financiación son algunos de los puntos calientes del sistema.

${ }^{\text {I2 }}$ G. Rodríguez Cabrero es uno de los autores que con más profundidad han estudiado el tema de la protección social a las personas dependientes en España. Su extensa obra aborda tanto el análisis sociodemográfico de la población dependiente como el estudio fino del coste, financiación y gestión del Sistema nacional de dependencia (SAAD). Por ejemplo, en el año 2005 mantuvo que el marco constitucional sí permitía materializar una cobertura universal de protección de las personas dependientes. Consideraba que la protección a la dependencia tiene un doble soporte constitucional. El artículo 4I de la Constitución Española (CE) permite 
I992, que concluyó con el Libro Blanco de la Dependencia (publicado a finales de 2004) y que encuentra en el diálogo social su apoyo fundamental, cuyos principios se encuentran en el pacto de Toledo de I995, Acuerdo de mejora de las pensiones de 200I, renovación del Pacto de Toledo en octubre de 2003 , el acuerdo de diciembre de 2005 entre organizaciones empresariales, sindicatos y el gobierno y, por último, las aportaciones del Defensor del Pueblo en el año 2000 así como las del Consejo Económico Social que ayudaron a enriquecer el debate; una revisión de datos que, a groso modo, coincide con los relatados en la exposición de motivos de la Ley de dependencia.

No obstante, en la exposición de motivos de la Ley de dependencia también se indica de manera expresa que en octubre de 2003 se aprobó en el Pleno del Congreso de los Diputados la Renovación del Pacto de Toledo con una Recomendación Adicional 3. ${ }^{a}$ indica que: «resulta por tanto necesario configurar un sistema integrado que aborde desde la perspectiva de globalidad del fenómeno de la dependencia y la Comisión considera necesaria una pronta regulación en la que se recoja la definición de dependencia, la situación actual de su cobertura, los retos previstos y las posibles alternativas para su protección».

El mismo texto legal relata que el 30 de mayo de 2000 se creó en el Congreso una Comisión no permanente para la valoración de los resultados obtenidos por la aplicación de las primeras Recomendaciones del Pacto de Toledo. El informe final elaborado por dicha Comisión, que recibe el nombre de Renovación del Pacto de Toledo, se fue aprobado por el Pleno del Congreso el 2 de octubre de 2003. En la Recomendación Adicional $3^{a}$ se indica que resulta necesario configurar un sistema integrado que aborde, desde la perspectiva de la globalidad, el fenómeno de la dependencia. Ello debe hacerse con la participación activa de toda la sociedad y con la implicación de la Administración Pública a todos sus niveles, todo ello a través de la elaboración de una política integral de atención a la dependencia en la que quede claramente definido el papel que ha de jugar el sistema de protección social en su conjunto.

A finales de 2004 fue publicado por el Instituto de Mayores y Servicios Sociales (Ministerio de Trabajo y Asuntos Sociales) el Libro Blanco, un texto que constituyó un hito y un impulso para la posterior elaboración de la Ley de Dependencia. En su redacción colaboraron las distintas Administraciones públicas, representantes de los sectores implicados, agentes sociales, universidades, instituciones y profesionales especializados en la materia.

El Libro Blanco, estructurado en doce capítulos, que constituyen una amplia panorámica sobre los aspectos demográfico ${ }^{\text {I3 }}$, las características y perfiles de la dependencia,

interpretar dicha protección como derecho subjetivo en el ámbito de la extensión y el perfeccionamiento de la seguridad social «para todos los ciudadanos» que precisen «asistencia y prestaciones sociales suficientes ante situaciones de necesidad».

El mismo autor, consciente de las dificultades presupuestarias y de las carencias de la red de servicios sociales para atender la dependencia, pronosticó que sin una red extensa de servicios sociales, la opción mayoritaria seguiría siendo durante mucho tiempo la de las prestaciones económicas, y difícilmente se lograría la eficacia protectora que se pretendía conseguir y, continuaba argumentando, que la protección social de la dependencia es una política de Estado que tiene su punto de partida en la regulación y financiación de las administraciones centrales de las prestaciones básicas, y su desarrollo y gestión tanto en las comunidades autónomas, que poseen la competencia en materia de servicios sociales, como en la administración local, en cuyo ámbito se proveen los servicios comunitarios y que representa la puerta de entrada en el sistema protector. En este modelo, el sector privado, tanto mercantil como sin ánimo de lucro, tiene un papel de colaboración en la gestión de servicios sociales, públicos y privados.

I3 Posteriormente, en la exposición de motivos de la Ley se recogerían muchos de los aspectos tratados en el Libro Blanco. «En España, los cambios demográficos y sociales están produciendo un incremento progresivo de la población en situación de dependencia. Por una parte, es necesario considerar el importante crecimiento de la población de más de $6_{5}$ años, que se ha duplicado en los últimos 30 años, para pasar de 3,3 millones de personas en I970 (un 9,7 por ciento de la población total) a más de 6,6 millones en 2000 (i6,6 por ciento). A ello hay que añadir el fenómeno demográfico denominado «envejecimiento del envejecimiento», es decir, el aumento 
el régimen jurídico, el llamado apoyo informal, los recursos disponibles, la atención sanitaria y la necesaria coordinación sociosanitaria; los presupuestos y recursos económicos dedicados a la dependencia por el sector público y los criterios y técnicas de valoración; sin olvidar la generación de empleo y retornos económicos que va a suponer el desarrollo de un Sistema de atención a las personas dependientes y un estudio comparado de los diferentes sistemas de protección en los países de nuestro entorno. Concluye con una serie de consideraciones finales que van a servir para la reflexión, el debate y, en su caso, la toma de decisiones políticas, económicas, administrativas, etc. sobre la atención a las personas dependientes.

Por otro lado, los debates previos a la aprobación del texto legal fueron intensos y extensos. Por ejemplo, desde un punto de vista jurídico, varios autores reconocen la habilitación del Estado para actuar en materia de política social y, sobre todo, de derechos sociales, pero también hay quienes dicen que la atención a la dependencia es inconstitucional.

A nivel político, se presentaron diferentes enmiendas a la totalidad del proyecto de ley que gravitaron sobre la injerencia del Estado al establecer una norma básica en un ámbito competencial propio de las comunidades autónomas. En este sentido se presentaron las enmiendas a la totalidad del Grupo Parlamentario Vasco (PNV-EAJ), del Grupo Parlamentario CIU y del Grupo Parlamentario Mixto (Eusko Alkartasuna).

Todas las enmiendas a la totalidad fueron rechazadas en el Pleno del Congreso de los Diputados (el 22 de junio de 2006) y la Ley fue aprobada votando en contra el PNV, CIU y EA. Esta Ley fue respaldada en el Congreso de los Diputados con 295 votos a favor, I5 en contra y una abstención. Un triunfo rotundo de una política social de calado articulada por el Gobierno socialista de José Luís Rodríguez Zapatero.

Otra de las estrategias políticas desplegadas sobre esta cuestión corrió a cargo de Unión del Pueblo Navarro que interpuso un recurso de «inconstitucionalidad» contra la Ley que fracasó.

El citado conflicto competencial no se resolvió con la aprobación parlamentaria de la Ley sino que, a día de hoy, sigue vigente y constituye el argumento de algunas autonomías para desviarse de la norma o reinterpretarla de una manera particular. ${ }^{14}$

Otro aspecto destacable en ese momento era la conciencia de que las administraciones públicas debían ofrecer una mayor oferta de servicios públicos para la dependencia argumentando que el gasto social a efectos estadísticos puede también considerarse inversión desde distintos puntos de vista dado que los servicios sociales, los recursos económicos que se emplean, producen un efecto multiplicador en la calidad de

del colectivo de población con edad superior a 80 años, que se ha duplicado en sólo veinte años. Ambas cuestiones conforman una nueva realidad de la población mayor que conlleva problemas de dependencia en las últimas etapas de la vida para un colectivo de personas cada vez más amplio. Asimismo, diversos estudios ponen de manifiesto la clara correlación existente entre la edad y las situaciones de discapacidad, como muestra el hecho de que más del $32 \%$ de las personas mayores de $6_{5}$ años tengan algún tipo de discapacidad, mientras que este porcentaje se reduce a un $5 \%$ para el resto de la población». Fuente: LAPAD.

${ }^{14}$ A juicio de expertos, también evidencia que la Administración General del Estado no despliegue un régimen jurídico mucho más concreto o no emplee la vía jurisdiccional para llamar la atención a quienes no están cumpliendo de manera correcta con los preceptos de la norma. En palabras de la Asociación Estatal de Directores y Gerentes de Servicios Sociales (2008): «La extremada cautela de la Administración Central con respecto a interferir lo menos posible en el ámbito competencial y la gestión de las comunidades autónomas está abriendo un panorama caótico que requiere una urgente intervención ordenadora por parte, al menos, del Consejo Territorial de la Dependencia». 
vida de las personas, en la generación de empleo y disminución importante del ahorro sanitario.

También se discutió el tema presupuestario. En 2005 se reconocía que el gasto de protección social a la dependencia era muy bajo y se creía que el coste estimado era asumible por el sistema de protección social y que, por lo tanto, lo crucial era crear un sistema institucional universal que garantizara la igualdad de acceso sin distinción de clases sociales, edades, etc., equilibrado territorialmente y coordinado entre las diferentes administraciones públicas.

Con esta urdimbre se confeccionó la trama de la Ley de dependencia. En el 2006, después de un largo proceso de consultas y pactos, vio la luz un nuevo derecho de los ciudadanos: el derecho de las personas dependientes a ser atendidas por los poderes públicos mediante el respaldo legal de la Ley de Promoción de la Autonomía Personal y atención a las Personas en situación de Dependencia.

II.I. El cuidado como derecho social ${ }^{15}$ reconocido en la Ley $39 / 2006$, de I4 de diciembre, de Promoción de la Autonomía Personal y atención a las personas en situación de dependencia

En la exposición de motivos de la LAPAD se establece que la atención a las personas en situación de dependencia y la promoción de su autonomía personal constituye uno de los principales retos de la política social de los países desarrollados ${ }^{\mathrm{I} 6}$. Y continua diciendo que el reto no es otro que atender las necesidades de aquellas personas que, por encontrarse en situación de especial vulnerabilidad, requieren apoyos para desarrollar las actividades esenciales de la vida diaria, alcanzar una mayor autonomía personal y poder ejercer plenamente sus derechos de ciudadanía.

Según la propia formulación de la Ley de dependencia, dependencia es el estado de carácter permanente ${ }^{\mathrm{I7}}$ en que se encuentran las personas que, por razones derivadas de la edad, enfermedad o discapacidad, y con falta de autonomía física, mental, intelectual o sensorial, necesitan la atención de una $u$ otras personas, o ayudas importantes para la

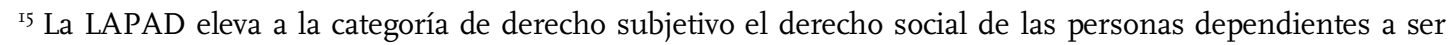
atendidas por los poderes públicos. «DERECHO SUBJETIVO: Poder o conjunto de facultades ostentado por un sujeto en virtud de una norma jurídica que posibilita no solo la realización de determinados actos para la satisfacción de intereses propios, sino también la exigencia, si así lo desea su titular, de su respeto por parte de otros sujetos a fin de que éstos no impidan lo admitido por el Derecho o la norma». DE LUCAS Y MURILLO DE LA CUEVA, F. Y ARIAS ASTRAY, A. (dir.) (20I0). Diccionario internacional de Trabajo social y servicios sociales. Buenos Aires, Miño y Dávila, pág. 45.

${ }^{16}$ DE EXPOSICIÓN DE MOTIVOS - El reconocimiento de los derechos de las personas en situación de dependencia ha sido puesto de relieve por numerosos documentos y decisiones de organizaciones internacionales, como la Organización Mundial de la Salud, el Consejo de Europa y la Unión Europea. En 2002, bajo la presidencia española, la Unión Europea decidió tres criterios que debían regir las políticas de dependencia de los Estados miembros: universalidad, alta calidad y sostenibilidad en el tiempo de los sistemas que se implanten. Las conclusiones del Informe de la Subcomisión sobre el estudio de la situación actual de la discapacidad, de 13 de diciembre de 2003 , coinciden en la necesidad de configurar un sistema integral de la dependencia desde una perspectiva global con la participación activa de toda la sociedad

${ }^{17}$ El Artículo2 la Ley 39/2006, de I4 de diciembre, de Promoción de la Autonomía Personal y Atención a las personas en situación de dependencia (LAPAD) define la dependencia como la situación permanente en la que se encuentran las personas que precisan ayudas importantes de otra $u$ otras personas para realizar las actividades básicas de la vida diaria. El término permanente elimina aquellas situaciones de dependencia transitorias, pudiendo dejar a estas personas y sus allegados sin cobertura de la ley. 
realización de las actividades de la vida diaria o, en el caso de las personas con discapacidad intelectual o enfermedad mental, de otras ayudas para su autonomía persona ${ }^{\mathrm{I} 8}$.

Dicho con otras palabras, la LAPAD establece un nuevo derecho para todos los ciudadanos que consiste en que todas las personas que no puedan valerse por sí mismas serán atendidas por las administraciones públicas (los poderes públicos), quienes tienen la obligación de garantizar el acceso a los servicios y a las prestaciones económicas más adecuadas a sus necesidades según criterios establecidos en la propia Ley de dependencia. ${ }^{\text {I9 }}$

La Ley de dependencia proporciona cobertura en todas las edades y a un amplio campo de discapacidades que limitan la autonomía, si bien son los mayores sus principales destinatarios porque, como indican los datos estadísticos, la correlación entre edad y discapacidad es muy elevada, sobre todo, a partir de los 80 años las tasas de prevalencia de la discapacidad aumentan considerablemente. ${ }^{20}$

Los límites para de acceso y posterior disfrute del derecho social derivado de la Ley se establecen mediante un baremos, común para todo el territorio nacional, que considera tres grados de dependencia: moderado, severo y gran dependencia, cada uno de los cuales consta de dos niveles en función de la autonomía y de la atención y cuidados que requiere la persona.

La LAPAD recoge también los parámetros por lo que se ha de regir el sistema de atención a la dependencia al indicar que el Estado se compromete a garantizar a los ciudadanos, y a las propias Comunidades Autónomas, un marco estable de recursos y servicios para la atención a la dependencia. Es decir, contrae la obligación de intervenir activamente en el desarrollo y consolidación de la política social de atención a la dependencia, ampliando con este compromiso las modalidades de protección social, ayudando al fortaleciendo el modelo de Estado social consagrado en la Constitución española y dando un nuevo impulso al Sistema público de servicios sociales ${ }^{21}$.

${ }^{18}$ El artículo 2.3 define las actividades instrumentales de la vida diaria como aquellas actividades más complejas que las ABVD, y su realización requiere de un mayor nivel de autonomía personal. Se asocian a tareas que implican la capacidad de tomar decisiones e implican interacciones más difíciles con el medio. En esta categoría se incluyen tareas domésticas, de movilidad, de administración del hogar y de la propiedad, como poder utilizar el teléfono, acordarse de tomar la medicación, cortarse las uñas de los pies, posibilidad de subir escalones, coger un autobús, un metro o un taxi, preparar la propia comida, comprar lo que se necesita para vivir, realizar actividades domésticas básicas (fregar los platos, hacer la cama, etc.), poder pasear, ir al médico, hacer papeleos y administrar el propio dinero, entre otras.

I9 En la exposición de motivos de la LAPAD se dice que la necesidad de garantizar a los ciudadanos un marco estable de recursos y servicios para la atención a la dependencia y su progresiva importancia, lleva ahora al Estado a intervenir en este ámbito con la regulación contenida en esta Ley, que la configura como una nueva modalidad de protección social que amplía y complementa la acción protectora del Estado y del Sistema de la Seguridad Social. Es decir, todas las personas, de hecho o potencialmente, con independencia del sexo y de la edad, pueden encontrarse en situación de dependencia, ya que ésta sobreviene como consecuencia de múltiples y variados factores: discapacidad, limitaciones en la actividad, restricciones en la participación, el entorno social, circunstancias culturales y sociales y otras análogas.

${ }^{20}$ Según se contempla en la exposición de motivos, la atención a este colectivo de población se convierte, pues, en un reto ineludible para los poderes públicos, que requiere una respuesta firme, sostenida y adaptada al actual modelo de nuestra sociedad y recuerda que, hasta ahora, han sido las familias, y en especial las mujeres, las que tradicionalmente han asumido el cuidado de las personas dependientes, constituyendo lo que ha dado en llamarse el «apoyo informal». Esta apuesta política no es casual. Los cambios en el modelo de familia y la incorporación progresiva de casi tres millones de mujeres, en la última década, al mercado de trabajo introducen nuevos factores en esta situación que hacen imprescindible una revisión del sistema tradicional de atención para asegurar una adecuada capacidad de prestación de cuidados a aquellas personas que los necesitan.

${ }^{2 \pi}$ Se pensó que el Sistema de Atención de la Dependencia es uno de los instrumentos fundamentales para mejorar la situación de los Servicios Sociales en nuestro país, respondiendo a la necesidad de la atención a las situaciones de dependencia y a la promoción de la autonomía personal, la calidad de vida y la igualdad de oportunidades. Hagamos un poco de historia. 
Asimismo, la LAPAD diseña el sistema de cuidados a las personas de pendientes. «Se trata ahora de configurar un nuevo desarrollo de los servicios sociales del país que amplíe y complemente la acción protectora de este sistema, potenciando el avance del modelo de Estado social que consagra la Constitución Española, potenciando el compromiso de todos los poderes públicos en promover y dotar los recursos necesarios para hacer efectivo un sistema de servicios sociales de calidad, garantistas y plenamente universales. En este sentido, el Sistema de Atención de la Dependencia es uno de los instrumentos fundamentales para mejorar la situación de los servicios sociales en nuestro país, respondiendo a la necesidad de la atención a las situaciones de dependencia y a la promoción de la autonomía personal, la calidad de vida y la igualdad de oportunidades» ${ }^{22}$.

\section{II.2. Breve descripción del Sistema para la Autonomía y Atención a la Dependencia $(\mathrm{SAAD})^{23}$}

El artículo i6 de la Ley de dependencia indica que la LAPAD no sólo establece prestaciones, de servicios y económicas, de promoción de la autonomía personal y atención a la dependencia, sino que crea un nuevo sistema, el Sistema para la Autonomía y Atención a la Dependencia (SAAD), lo cual significa que dota de mayor fuerza jurídica e institucional a las prestaciones de autonomía personal y atención a la dependencia. Este sistema se encuentra estrechamente vinculado a los sistemas autonómicos de Servicios Sociales.

La creación del SAAD se contempla al comienzo de la Ley de Dependencia (artículo I.I): «La presente Ley tiene por objeto regular las condiciones básicas que garanticen la igualdad en el ejercicio del derecho subjetivo de ciudadanía a la promoción de la autonomía personal y atención a las personas en situación de dependencia, en los términos establecidos en las leyes, mediante la creación de un Sistema para la Autonomía y Atención a la Dependencia, con la colaboración y participación de todas las Administraciones Públicas y la garantía por la Administración General del Estado de un contenido mínimo común de derechos para todos los ciudadanos en cualquier parte del territorio del Estado español».

La Ley de Dependencia establece que el Sistema para la Autonomía y Atención a la Dependencia responderá a una acción coordinada y cooperativa de la Administración General del Estado y las Comunidades Autónomas, que contemplará medidas en todas las áreas que afectan a las personas en situación de dependencia, con la participación, en su caso, de las Entidades Locales.

Asimismo, dedica un artículo específico (artículo 6) a determinar la finalidad del SAAD en los siguientes términos: «I. El Sistema para la Autonomía y Atención a la Dependencia garantiza las condiciones básicas y el contenido común a que se refiere la presente Ley; sirve de cauce para la colaboración y participación de las Administraciones Públicas, en el ejercicio de sus respectivas competencias, en materia de promoción de la

Los servicios sociales constituyen en España una rama en transición hacia un sistema coherente de protección social. Su precedente, la asistencia social, tiene una larga e importante tradición histórica, pero casi siempre asociada a la beneficencia, institucionalmente fragmentada y constreñida por una discrecionalidad administrativa relativa y un limitado impacto social.

La constitucionalización de los servicios sociales en 1978 y las leyes de servicios sociales de las comunidades autónomas supusieron el inicio de un largo proceso de modernización y expansión de los servicios sociales. Pero no es hasta recientemente cuando la expansión de los servicios sociales, con una importante debilidad financiera e institucional, inician un proceso riguroso de institucionalización al que contribuyen la LAPAD y la última generación de leyes autonómicas de servicios sociales. Cambios que se inscriben en las tendencias de transformación del sistema de servicios sociales en los regímenes de bienestar del Modelo Social Europeo.

${ }^{22}$ Exposición de motivos LAPAD.

${ }^{23}$ Las anotaciones de este apartado están extraídas de la página web del Ministerio de Sanidad, Servicios Sociales e Igualdad http://www.dependencia.imserso.es/dependencia_or/index.htm 
autonomía personal y la atención y protección a las personas en situación de dependencia; optimiza los recursos públicos y privados disponibles, y contribuye a la mejora de las condiciones de vida de los ciudadanos. 2. El Sistema se configura como una red de utilización pública que integra, de forma coordinada, centros y servicios, públicos y privados».

El SAAD no tiene únicamente órganos gestores centrales, ni tampoco autonómicos o locales. Su actuación gestora se ha configurado bajo el principio de coordinación interadministrativa. Por esta razón la Ley de Dependencia (artículo 8.I) crea el Consejo Territorial de Servicios Sociales y del SAAD como instrumento de cooperación para la articulación del sistema. Está constituido por representantes de la Administración General del Estado y de las Comunidades Autónomas. ${ }^{24}$

El SAAD se financia con cargo a tres fuentes: los créditos que anualmente se fijan en los Presupuestos Generales del Estado, los Presupuestos de cada Comunidad Autónoma, y las aportaciones de los usuarios. Estas últimas se efectúan en función de su capacidad económica personal, y del tipo y el coste del servicio correspondiente, sin que en ningún caso pueda verse privado del servicio por falta de recursos económicos suficientes. La capacidad económica personal del beneficiario se tiene en cuenta también para determinar la cuantía de las prestaciones económicas que le puedan ser concedidas.

La propia Ley en su preámbulo afirma que la financiación será estable, suficiente, sostenida en el tiempo y garantizada mediante corresponsabilidad de las Administraciones públicas.

Respecto de las personas beneficiarias, el acceso al SAAD se basa en el derecho social subjetivo a la acción protectora que garantiza una protección mínima materializada en un conjunto de prestaciones sociales, económicas y servicios. El acceso al SAAD tiene lugar mediante un proceso relativamente complejo solicitado por la persona afectada o su tutor y que se descompone en tres fases: valoración de la situación de dependencia, reconocimiento de la misma y definición del programa individual de atención o PIA. La persona en situación de dependencia beneficiaria y con un PIA puede materializar las prestaciones acordadas entre la persona afectada y el equipo profesional, cuya garantía mínima está asegurada por la AGE y de manera complementaria y en la misma cantidad al menos por las comunidades autónomas que pueden de manera adicional completar la acción protectora implicando a la persona afectada mediante el copago. Estos tres niveles de protección: mínimo garantizado por la AGE, nivel convenido entre ésta y cada comunidad autónoma y el adicional libre por cada comunidad autónoma es expresión del modelo competencial acordado en el diseño de la LAPAD. ${ }^{25}$

${ }^{24}$ El SAAD es un sistema de protección social complejo que se basa en el reparto de competencias entre el AGE (Administración General del Estado) y las comunidades autónomas. Para hacer compatibles las competencias exclusivas de las comunidades autónomas en materia de servicios sociales y la garantía de igualdad en todo el territorio del Estado la LAPAD adoptó un sistema de competencias basado en el principio de cooperación entre administraciones en el ejercicio de sus respectivas competencias. De este modo la LAPAD no es una ley básica pues el Estado no reclama competencia alguna exclusiva en esta materia, que tiene que compartir con las comunidades autónomas, pero tampoco queda subordinado a éstas en la medida en que apela a su competencia de regular las condiciones básicas que garantizan la igualdad en el ejercicio de derechos que limiten la diversidad existente en el conjunto del Estado. Esto abre una fórmula de gobierno necesariamente cooperativo basado en competencias compartidas y en el principio de lealtad institucional.

${ }_{25}$ Para ser beneficiario de los servicios y prestaciones han de cumplirse los requisitos que establece con carácter general la Ley de Dependencia. Son los siguientes: a) Encontrarse en situación de dependencia en alguno de los grados establecidos. b) Residir en territorio español y haberlo hecho durante cinco años, de los cuales dos deberán ser inmediatamente anteriores a la fecha de presentación de la solicitud. Para los menores de cinco años el periodo de residencia se exigirá a quien ejerza su guarda y custodia. c) Las personas que, reuniendo los requisitos anteriores, carezcan de la nacionalidad española se regirán por lo establecido en la Ley Orgánica 4/2000, de II de enero, sobre derechos y libertades de los extranjeros en España y su integración social, en los tratados internacionales y en los convenios que se establezcan con el país de origen. Para los 
En cuanto a los servicios y prestaciones, el SAAD tienen como finalidad promover la autonomía personal y mejorar la calidad de vida de las personas, en atención a sus dificultades para la realización de las actividades básicas de la vida diaria, en un marco de efectiva igualdad de oportunidades y de acuerdo con los objetivos de facilitar una existencia autónoma en su medio habitual, todo el tiempo que desee y sea posible y proporcionar un trato digno en todos los ámbitos de su vida personal, familiar y social, facilitando su incorporación activa en la vida de la comunidad.

Las prestaciones de atención a la dependencia podrán tener la naturaleza de servicios y de prestaciones económicas; los primeros tienen carácter prioritario. ${ }^{26}$

La prioridad en el acceso a los servicios vendrá determinada por el grado de dependencia y, a igual grado, por la capacidad económica del solicitante. Hasta que la Red de Servicios del SAAD esté totalmente implantada, las personas en situación de dependencia que no puedan acceder a los servicios por aplicación del régimen de prioridad señalado, tendrán derecho a una prestación económica vinculada al servicio.

Asimismo las personas beneficiarias participarán en el coste de los servicios según el tipo y coste del servicio y su capacidad económica personal. El legislador no se olvida de un aspecto importante: la acreditación de Centros y servicios con objeto de prestar unos servicios de calidad y con calidad por parte de las Administraciones Públicas, por tanto el Sistema para la Autonomía y Atención a la Dependencia (SAAD) garantiza tanto la calidad de sus recursos como de las condiciones en que se prestan sus servicios. ${ }^{27}$

En cuanto a la cualificación profesional exigida a los recursos humanos de los Centros y Servicios del SAAD, por Resolución de 2 de diciembre de 2008 , se contempla la profesionalización de los recursos humanos del sistema, para garantizar la calidad del

menores que carezcan de la nacionalidad española se estará a lo dispuesto en las Leyes del Menor vigentes, tanto en el ámbito estatal como en el autonómico, así como en los tratados internacionales. d) El Gobierno podrá establecer medidas de protección a favor de los españoles no residentes en España. e) El Gobierno establecerá, previo acuerdo del Consejo Territorial de Servicios Sociales y del Sistema para la Autonomía y Atención a la Dependencia, las condiciones de acceso al Sistema de Atención a la Dependencia de los emigrantes españoles retornados.

${ }^{26}$ El reconocimiento del derecho a la acción protectora se materializa en un conjunto de prestaciones, económicas y en servicios, que se integran y gestionan en el sistema de servicios sociales como una red pública en la que participa la iniciativa privada. Los servicios se definen a partir del catálogo de servicios. Entre las novedades de las prestaciones destacar la prestación económica del asistente personal y la prestación económica vinculada al servicio. El SAAD no contempla las prestaciones sociosanitarias entendiendo que son competencia de las comunidades autónomas. Los servicios del Catálogo que se detallan en el artículo i5 de la Ley de Dependencia, tienen carácter prioritario y se prestarán a través de la oferta pública de la Red de Servicios Sociales por las respectivas Comunidades Autónomas mediante centros y servicios públicos o privados concertados debidamente acreditados.

El Catálogo de Servicios comprende los siguientes servicios sociales de promoción de la autonomía personal y de atención a la dependencia: Los servicios de prevención de las situaciones de dependencia y los de promoción de la autonomía personal. Servicio de Teleasistencia. Servicio de Ayuda a domicilio. Servicio de Centro de Día y de Noche. Servicio de Atención Residencial.

El SAAD contempla tres tipos de prestaciones económicas: Prestación económica vinculada al servicio. Prestación económica para cuidados en el entorno familiar y apoyo a cuidadores no profesionales. Prestación económica de asistencia personal.

${ }^{27}$ El SAAD está integrado por los centros y servicios públicos de las Comunidades Autónomas -en las ciudades de Ceuta y de Melilla por los Centros y Servicios del Imserso-, Entidades Locales, centros de referencia estatal para la promoción de la autonomía personal y para la atención y cuidado de las situaciones de dependencia, así como por los privados concertados debidamente acreditados. Las entidades, centros y servicios privados podrán integrarse en la Red de servicios del SAAD siempre que cuenten con la correspondiente acreditación; esta acreditación garantiza el derecho de las personas en situación de dependencia a recibir unos servicios de calidad ya que implica el cumplimiento de unos requisitos y unos estándares de calidad. La acreditación es la condición legal para que puedan prestar servicios a personas en situación de dependencia y que éstas puedan percibir la prestación económica de carácter personal vinculada a la adquisición de un servicio. Corresponde a las Comunidades Autónomas acreditar a los centros, servicios y entidades, si bien los criterios comunes de acreditación han sido acordados por el Consejo Territorial de Servicios Sociales y del SAAD. 
mismo, a través de la formación profesional, la cualificación profesional y los certificados profesionales, requiriéndose, para las categorías profesionales que no se correspondan con titulaciones universitarias.

Y ya para terminar este breve recorrido por el SAAD señalar la existencia de Centros de Referencia Estatal. Los Centros de Referencia Estatal (CRE) son dispositivos de servicios sociales creados por el Ministerio de Sanidad, Servicios Sociales e Igualdad, a través del Instituto de Mayores y Servicios Sociales, con el fin de promover en todos los territorios de las Comunidades y Ciudades Autónomas en que se articula el Estado español la innovación y mejora de la calidad de los recursos dirigidos a un sector determinado de personas en situación de dependencia. En el momento de implementar el SAAD unos estaban en funcionamiento y otros en proyecto o en construcción.

\section{II.3. El modelo español de atención a la dependencia en perspectiva comparada}

En líneas generales, en Europa existen tres modelos de cobertura de las demandas generadas por la dependencia: modelo universalista, modelo de protección social y modelo asistencialista.

El modelo universalista se caracteriza por financiarse a través de impuestos y por estar fundado en el principio de ciudadanía, su cobertura es universal. Es un sistema fundamentalmente de prestación de servicios, opta por la profesionalización del cuidado social, con un alto nivel de calidad asistencial y diferentes categorías ocupacionales ajustadas a las necesidades de los cuidados de larga duración. Los empleos son en su mayoría del sector público y la gestión de los servicios sociales suele ser competencia de las autoridades locales. Este modelo universalista es propio de los estados de bienestar socialdemócratas de los países escandinavos, con una fuerte tradición en garantizar derechos sociales a través de una noción de ciudadanía asentada en el principio integrador de solidaridad social. El principal impedimento para la implantación y sostenimiento del sistema es su elevado gasto social.

El modelo de protección social predomina en países como Alemania, Austria y, hasta cierto punto, Francia. En estos países, el cuidado de las personas dependientes se concibe como un seguro a la dependencia, quedando integrado en la seguridad social como una forma más de aseguramiento, equivalente a las pensiones de vejez, de invalidez o a las prestaciones por desempleo. Se financia a través de cotizaciones de trabajadores y empresarios, y no vía impuestos generales como en el caso universalista. Además, aunque se proporcionan servicios directos, la dependencia se articula fundamentalmente a través de prestaciones económicas, bien directamente a la persona que necesita cuidados o bien a la familia cuidadora o profesional que realice las tareas de cuidado. Las prestaciones tienen un tope, y la situación de dependencia se evalúa en grados o niveles de gravedad, de los que se derivan prestaciones monetarias de diferente cantidad o servicios de distinta intensidad o duración. La gestión de las prestaciones está centralizada, pero los servicios se encuentran descentralizados en las administraciones territoriales.

El modelo asistencialista se caracteriza por proporcionar una cobertura limitada a aquellas personas en situación de dependencia, con insuficientes recursos económicos. En este modelo opera el principio de subsidiariedad ${ }^{28}$, según el cual el Estado interviene sólo cuando la familia, entendida de manera amplia, es incapaz de administrar cuidado. Su limitado alcance se amortigua parcialmente por las organizaciones privadas, financiadas

${ }^{28}$ SUBSIDIARIO/A. Acción o responsabilidad que suple o refuerza otra principal. En el caso que nos ocupa, el Estado desempeñaba una acción subsidiaria respecto de la Beneficencia y la caridad. 
muchas veces con fondos públicos. Este es el modelo que predomina en los países mediterráneos, incluida España antes de la LAPAD y el SAAD.

Ahora bien, a pesar de las divergencias entre los tres modelos, la política social de protección a la dependencia revela en el ámbito europeo ciertos rasgos comunes, como la descentralización de la gestión hacia niveles administrativos locales y el sector privado, o la ampliación de la capacidad de decisión de los destinatarios de las políticas así como de sus familiares.

Por otro lado, en la configuración de los modelos se dejan sentir las directrices europeas en tanto en cuanto tienden a recalcar la importancia de la universalización de los derechos, de la accesibilidad generalizada a los recursos de protección y de la sostenibilidad financiera de los sistemas protectores. ${ }^{29}$

En suma, derecho subjetivo al reconocimiento y protección de las situaciones de dependencia, descentralización del sistema protector, provisión mixta, centralidad de la atención personal o gestión del caso y libertad de elección, constituyen rasgos dominantes en el conjunto del modelo europeo de cuidado de larga duración, del que también participa España..$^{30}$

El modelo español de atención a la dependencia configurado y desarrollado en la LAPAD y el SAAD se sitúa en la senda de los modelos europeos universalistas y de protección social, una apuesta de política social que ha supuesto, un esfuerzo presupuestario notable sino también un cambio profundo en las estructuras organizativas del Sistema público de servicios sociales mediante el diseño de un complejo sistema descentralizado de colaboración entre Administraciones públicas (AGE, comunidades autónomas y corporaciones locales) y ámbitos del bienestar (sanidad, servicios sociales y seguridad social) que, por un lado, complejiza enormemente la organización de un sistema unificado y coordinado de la dependencia y, por otro, abre la puerta a la posibilidad de la

29 Para profundizar en los modelos de atención a la dependencia en Europa es recomendable la lectura del libro de Ana Arribas y F. J. Moreno. El tratamiento de la dependencia en los regímenes de bienestar europeos contemporáneos. Madrid, Ministerio de Sanidad, Política social e Igualdad, 2009.

También es recomendable la revisión de la normativa comunitaria en materia de servicios sociales de interés general.

$3^{30}$ Parafraseando a Rodríguez Cabrero (20II), el desarrollo de los sistemas nacionales de dependencia en la Unión Europea, sobre todo los de cobertura universal, bien nórdicos bien continentales, son ramas de protección social que se han desarrollado a partir de dos realidades: a) En primer lugar, la importancia histórica de la familia en los cuidados de las personas mayores frágiles o en situación de dependencia. Esta protección de la familia se está adaptando a la incorporación de la mujer al mercado de trabajo, que era y es la cuidadora principal, a la vez que aquella encuentra en el sector servicios oportunidades de empleo; hay que recordar que el ochenta y seis por cien de todo el empleo en los servicios sociales es femenino, es decir, tiene una clara connotación de género. Este elemento, hay que insistir en ello, sigue siendo central: la familia, si no como cuidadora directa en muchos casos, sigue siendo el factor por excelencia de organización de los cuidados personales y de su propia prestación informal. La elección mayoritaria de las personas en situación de dependencia a favor de vivir en el propio domicilio tiene mucho que ver con soporte familiar directo o a distancia y control Sector servicios; b) en segundo lugar, el desarrollo de los sistemas nacionales de atención a la dependencia nace en un contexto histórico de profunda reestructuración del Estado de bienestar que ha llevado a formas de financiación que implican a la persona protegida o su familia, que asumen una parte del coste en función de los recursos y que, como consecuencia, junto a otros factores de cambio cultural, refuerzan la libertad de elección entre las prestaciones sociales disponibles y ofertadas por los sistemas públicos.

Un sistema de protección social basado en el derecho subjetivo que garantiza un conjunto de prestaciones en especie o en dinero en función del grado y nivel de dependencia, bajo modelos competenciales en los que el Estado garantiza una financiación, además de la igualdad en el territorio del Estado; las regiones o comunidades tienen la plena responsabilidad de la planificación y gestión; y los ayuntamientos son el punto de entrada en el sistema y de provisión de los servicios comunitarios o básicos. En algunos modelos, como el nórdico, son los ayuntamientos la autoridad por excelencia del sistema de protección a la dependencia o de cuidados de larga duración. 
innovación política y la mayor eficacia en la gestión de los propios recursos a escala autonómica y local. ${ }^{3 \mathrm{I}}$

Por lo demás, el modelo español se ha implementado en paralelo con la tradición asistencialista y familiarista ${ }^{32}$ de nuestro país y su puesta en práctica ha puesto de relieve las «luces y las sombras» de un sistema que ha querido compaginar tradición y modernidad.

\section{Luces y sombras en la implementación del sistema nacional de atención a la dependencia (SAAD) $)^{33}$}

La Ley 39 /2006, de I4 de diciembre, de Promoción de la Autonomía Personal y atención a las personas en situación de dependencia y el desarrollo del SAAD han sido dos hitos históricos que han propiciado el desarrollo de un sistema público de atención a las personas dependientes. ${ }^{34}$

Como puntos fuertes de esta política social destacamos, en primer lugar, la consideración del cuidado como responsabilidad pública, el enfoque comunitario del cuidado derivado de la implementación actual del sistema y la ampliación de la cobertura de atención a las necesidades de las personas dependientes mediante la revisión de las algunas estadísticas nacionales del SAAD.

- El cuidado es una responsabilidad pública.

Como hemos señalado en este escrito, tradicionalmente la actividad del cuidado y la atención de las situaciones de dependencia quedaba relegada al ámbito privado, fruto también de una división sexual del trabajo en la que la mujer era responsable de la prestación de ayuda y cuidado de sus familiares y seres queridos. Con la Ley de dependencia y el desarrollo del SAAD la intervención pública deja de ser complementaria o subsidiaria. Con este cambio de criterio se pasa de un modelo asistencialista a otro de bienestar. Dicho de otro modo, la política social de atención a la dependencia surgida con la promulgación de la Ley de dependencia permite superar el modelo cuyas acciones de protección daban cuenta de la asistencia social entendida como aquellas actividades administrativas encaminadas a auxiliar, con cargo a fondos públicos, a aquellas personas que no se encuentran en condiciones de satisfacer sus necesidades, incluso las más básicas para el desarrollo de una vida cotidiana autónoma.

Igualmente se pasa del reconocimiento de derechos condicionados ${ }^{35}$ a derechos subjetivos. Con esta distinción se pone de manifiesto que la asistencia social se rige por

\footnotetext{
${ }^{31}$ Un ejemplo de la complejidad de la estructura organizativa cabe reseñar que mientras los servicios sociales permanecen como competencia autonómica y la administración central no puede ir más allá de la regulación de unos mínimos y de la coordinación entre comunidades, las prestaciones económicas quedarán centralizadas en la seguridad social, aunque gestionadas desde los gobiernos autonómicos y las corporaciones locales.

${ }^{32}$ Término atribuido a Gosta Esping-Anderser.

${ }^{33}$ Con objeto de no alargar excesivamente el texto, para abordar las «luces» de la Ley de dependencia hemos seleccionado tres aspectos destacados: a) el cuidado como responsabilidad pública, b) el enfoque comunitario del cuidado y c) estadísticas nacionales del SAAD. Por su parte, en el abordaje de las «sombras» centramos el discurso en: a) financiación del SAAD, b) complejidad de la gestión administrativa del SAAD y c) estado actual de la opinión pública sobre la política pública de atención a la dependencia mediante la presentación de algunas noticias recientes aparecidas en el diario El País sobre las debilidades del sistema.
}

34 Pese a las sombras que planean en torno a la política social de atención a la dependencia, no nos cansaremos de repetir que, a nuestro juicio,m la implementación de la Ley de dependencia constituye el más importante aporte social al Estado de Bienestar de los últimos años.

35 Expresión utilizada por ROLDÁN, E. Y GARCÍA, T. (2006) autoras que definen estos derechos condicionados como aquellos que están sometidos a la suficiencia de recursos económicos, se otorgan con 
derechos condicionados mientras que la Ley de dependencia reconoce el derecho subjetivo fundamentado en los principios de universalidad, equidad y accesibilidad, desarrollando un modelo de atención integral al ciudadano dependiente. Es decir, la Ley de dependencia reconoce el derecho subjetivo, no sujeto a otra condición que la de ciudadano, reclamable ante los tribunales y exigible ante la administración pública responsable. Un amparo de la Ley que obliga a enfocar la política social de una forma diferente al periodo anterior.

- Cambio de modelo de atención a la dependencia: de la institucionalización y el familiarismo al enfoque comunitario.

Tal como ha quedado reflejado en estas páginas, históricamente, la institucionalización o el internamiento fue la respuesta mayoritaria de las sociedades para la atención (y control) de aquellos individuos que se encontraban en situaciones determinadas de vulnerabilidad; instituciones, tales como hospicios, hospitales, orfanatos o asilos, encerraban entre sus paredes a individuos enfermos, pobres, huérfanos, ancianos desahuciados e inútiles. Con el tiempo se impone la concepción comunitaria de entender los cuidados y las atenciones a las personas.

El enfoque comunitario del cuidado se arraiga en las costumbres culturales de la comunidad y consiste en que la persona mayor, con discapacidad y/o en situación de dependencia permanezca el mayor tiempo posible en su propio domicilio y/o en su entorno habitual, promoviendo para ello toda una serie de servicios y apoyos (a las personas y a las familias) que se prestan en el ámbito de la comunidad: servicios de ayuda a domicilio, teleasistencia, centros de día, tratamientos ambulatorios, etc., pero también medidas de conciliación y otros recursos dirigidos a las familias, que son aquellas que soportan el peso principal de los cuidados. ${ }^{36}$

\section{- Datos estadísticos del SAAD.}

El número de personas atendidas por el SAAD se ha ido incrementando con el tiempo. Según datos publicados por el Ministerio de Sanidad, Servicios Sociales e Igualdad relativos a los cuatro primeros años de aplicación de la Ley de dependencia, cuatro de cada cinco personas reconocidas como grandes dependientes reciben ya las prestaciones de la Ley de Dependencia; las personas beneficiarias son mayoritariamente mujeres (67\%) con edades superiores a los 80 años, la mayor parte de las personas beneficiarias (más de 260.000 , el 39,50 \% del total) viven en localidades de más de 50.000 habitantes y 28 ,to \% del total de beneficiarios viven en municipios de menos de 5.000 habitantes; sólo un 0,36 $\%$ de las personas beneficiarias son extranjeras de las cuales $28,74 \%$ tienen más de 80 años frente al $56,23 \%$ general; cuatro de cada cinco personas reconocidas como grandes dependientes (Grado III) reciben las prestaciones del SAAD a las que tienen derecho y el 70 $\%$ de las personas con dependencia severa (Grado II); en este tiempo de análisis se han prestado 4I4.277 servicios y 385.732 prestaciones económicas, del total de prestaciones económicas 384.985 son de cuidados en el entorno familiar (48,12 \% del total), los servicios de atención residencial se prestan especialmente a personas con una elevada dependencia,

carácter discrecional cuando no de forma arbitraria, no están reconocidos en el marco constitucional como tales derechos y no están sujetos a la defensa jurídica.

${ }^{36}$ El enfoque comunitario ha estado presente, desde el principio, en la aplicación de la Ley de Dependencia, de tal manera que la prestación económica para cuidados en el entorno familiar ha sido hasta ahora la prestación que se ha concedido de una manera dominante. El 46,08\% del total de las prestaciones ha sido para ésta, abarcando a un total de 4I9.787 personas, habiendo incluso en determinadas comunidades autónomas momentos en que 3 de cada 4 prestaciones/servicios concedidos eran prestaciones económicas para cuidados en el entorno familiar. A la concepción afianzada en el imaginario colectivo (desde antes la aprobación de la ley) de que ésta iba a consistir principalmente en una «paguita» para los cuidadores, junto al deseo, tanto de cuidadores como de personas dependientes, de mantenerse en el hogar familiar y el entorno más cercano, ha permitido la proliferación de las mismas frente a otros recursos. 
en cambio, en las personas con Grado II Nivel I, sólo un 8,83 \% reciben este servicio, por sexos no existen grandes diferencias en cuanto a los servicios que reciben ${ }^{37}$; hasta finales de 2010, el Estado ha aportado 5.390.510.668 euros para financiar la atención a la dependencia, cantidad que supera en más de un $60 \%$ lo previsto en la memoria económica como aportación de la Administración General del Estado al SAAD.

Pero, junto a estos puntos fuertes planean también algunas debilidades del sistema. En este caso, hemos seleccionado tres aspectos: a) financiación del SAAD, b) complejidad de la gestión administrativa del SAAD y c) estado de opinión sobre la política pública de atención a la dependencia mediante la presentación de algunas noticias recientes aparecidas en el diario El País que hablan por sí solas sobre las debilidades del sistema.

\section{- La financiación ${ }^{38}$}

El Sistema para la Autonomía y Atención a la Dependencia que establece la Ley de la Dependencia se financia, además de las aportaciones de los dependientes, mediante transferencias en tres fondos principales: un nivel mínimo, un nivel acordado y otras aportaciones adicionales.

Los recursos del nivel acordado se están distribuyendo, entre otras variables de menor relevancia, en función de la población potencialmente dependiente y, en menor medida en función de la población dependiente ya evaluada. A juicio de los expertos, esta circunstancia ha provocado que algunas Comunidades Autónomas hayan podido tener déficit de financiación mientras que otras han sido excedentarias.

Puesto que las prestaciones de Servicios sociales son competencias asumibles por las CCAA (art. I48.I.2o de la Constitución Española), ha sido necesario establecer un marco general de financiación del servicio que señale no sólo las fuentes de financiación o la distribución de recursos de la Administración General del Estado sino que garantice también cierta homogeneidad en las prestaciones.

Dado que los servicios a la dependencia son un derecho subjetivo, universal, exclusivo de los individuos que tienen derecho a los mismos y lo han consolidado, el

37 Datos noviembre 20I0:

Prestaciones económicas para cuidados en el entorno familiar $49 \%$

Prestaciones económicas vinculadas a un servicio $6,7 \%$

Prestaciones económicas asistente personal o,I \%

Prestaciones en servicio de ayuda a domicilio 5,6\%

Prestaciones en servicios (centros de día) 5,7\%

Teleasistencia I0,7\%

Atención residencial I5,3\%

Fuente: Ministerio de Sanidad, Política social e Igualdad, SAAD-IMSERSO.

$3^{8}$ «Para entender de dónde viene el problema y lo que habría que cambiar, conviene esbozar la estructura del actual sistema de financiación regional español. El modelo vigente tiene cuatro elementos básicos. El primero es un reparto de recursos y de competencias tributarios entre administraciones que determina la capacidad fiscal bruta de las comunidades autónomas y su margen para subir o bajar impuestos. El segundo es una fórmula de necesidades de gasto que cuantifica los recursos que se consideran necesarios en cada región para financiar un nivel uniforme de servicios públicos en todo el territorio nacional. Esta regla se instrumenta a través del cálculo de una variable de población ajustada que sustituye a la población real de cada territorio a efectos de muchos de los cálculos que exige el sistema de financiación. Los dos últimos elementos son una serie de transferencias que fluyen horizontalmente (entre regiones) y verticalmente (de la administración central hacia las regiones) cuyo objetivo teórico es el de igualar los recursos con los que cuentan territorios con distintos niveles de renta para prestar los servicios de su competencia -o lo que es lo mismo, el de reducir la brecha existente entre necesidades de gasto y recursos». «Enrique Florez. Sobre el reparto de la tarta». El País I2/II/2OI2

Según datos del Ministerio de Sanidad, Servicios sociales e Igualdad, desde enero de 2007 hasta el 3I de diciembre de 20I0, en el sector de servicios sociales asociados a la dependencia se han producido 260.406 nuevas altas a la Seguridad social, de ellas iıo.84I corresponden a nuevas afiliaciones en el Régimen General y I49.565 personas se han dado de alta en el convenio especial de cuidadores no profesionales. 
sistema de financiación debe recoger esta peculiaridad, que lo diferencia del resto de Servicios sociales, por lo que la población dependiente ha sido la variable con mayor peso en todos los acuerdos. Sin embargo, en los primeros años de implantación del SAAD esta variable no se obtenía del censo de dependientes sino que su valor se conseguía de una estimación de la población dependiente de cada Comunidad Autónoma por tramos de edad.

El peso otorgado a la variable relativa población potencialmente dependiente (estimada) ha ido reduciéndose de forma progresiva en los sucesivos acuerdos de financiación. Simultáneamente, el peso del número real de dependientes reconocidos por cada Comunidad Autónoma ha crecido desde la implantación del SAAD. ${ }^{39}$

- Complejidad del modelo de gestión intergubernamental.

El SAAD contempla un modelo de gobierno complejo que debe articular tres Administraciones públicas: la Administración General del Estado y las Comunidades autónomas y éstas y los Ayuntamientos.

Así por ejemplo, el sistema competencial en materia del SAAD supone un esfuerzo de concurrencia desigual entre las distintas comunidades autónomas y la AGE que afecta al ritmo de implantación del nuevo sistema y a los modelos de prestaciones por lo que opta pues no hay que olvidar que la LAPAD no solo supone la puesta en marcha de una nueva rama de protección social sino al mismo tiempo promover el desarrollo del conjunto de los Servicios sociales.

\section{- Datos de opinión.}

Los ecos de sociedad dibujan un escenario incierto y controvertido. A título indicativo, reproducimos algunos titulares del periódico El País elegidos al azar, un comentario recogido de la página virtual del CGTS (Consejo General de Trabajadores Sociales) y una nota de prensa extraída de la página virtual del Ministerio de Sanidad, Servicios Sociales e Igualdad.

- «La patronal de la dependencia denuncia la falta de sensibilidad del Consell. La deuda de Ioo millones de la Generalitat pone en peligro I5.000 puestos de trabajo de 200 empresas». El País 23/II/20I2.

- «Cospedal impone tasas para tramitar la dependencia. Los usuarios que quieran revisar su situación y las ayudas que reciben tendrán ahora que pagar por ello». El País 22/IO/2OI2.

- «El sistema de dependencia pierde casi 5.000 usuarios al mes. Hay cerca de I00.000 personas esperando a ser evaluadas. Todos los capítulos están en números rojos». El País I8/10/20I2.

- «Los empresarios ofrecen a Rajoy un plan para ocupar las camas de los geriátricos. La patronal de la dependencia calcula que financiar el sector con 700 millones generaría retornos por 792 y se crearían 38.500 empleos inmediatos». El País 15/09/2012.

${ }^{39}$ Los problemas en este sentido y los diferentes sistemas de volcado de datos al Sistema de Información del SAAD (SISAAD) por parte de las Comunidades Autónomas, han dado lugar a más de una crítica que incluso ha tenido amplia repercusión en la prensa nacional. 
- «La dependencia pierde otros 200 millones para 2013. Los presupuestos del Estado reflejan la rebaja de las ayudas decretada en julio. Sanidad debe pagar a la Seguridad Social I.034 millones por las cotizaciones de los cuidadores». El País 27/09/20I2.

- «La Ley de Dependencia puede generar más de 600.000 empleos. España, por debajo de la media europea en atención a la dependencia según un informe de la Fundación Alternativas». El País 25/09/2012.

- «Parece que esperan resolver la dependencia mediante fallecimientos. El presidente de la Federación Empresarial de la Dependencia advierte de que el sector no puede asumir más recortes». El País I8/09/2012.

- «Adiós, Dependencia, adiós. España no puede permitirse perder la oportunidad de invertir en uno de los poquísimos sectores con capacidad para generar riqueza». El País 3/08/2012.

- «Los presupuestos que ha aprobado el Gobierno condenan a muerte a la Ley de Dependencia. Los trabajadores sociales exigen al Gobierno que recapacite y no haga caer el peso de los recortes a quienes más ayuda necesitan. Se recortan 236 millones en ayudas directas a las familias de los dependientes. Las autonomías recibirán 200 millones menos del Estado, lo que repercutirá en menos ayuda. Los planes de envejecimiento activo y promoción de la autonomía personal contarán con 9,6 millones menos». CGTS (Consejo General de Trabajadores Sociales) 28/9/2012.

- «El sistema de Dependencia arrastraba un gasto de 2.700 millones de euros más de los previstos, por eso acometimos una reforma para hacer sostenible una ley que nació con el consenso de todos». Nota de prensa del Ministerio de Sanidad, Servicios sociales e Igualdad, 30/10/2012.

\section{A modo de balance}

Del recorrido, sectorizado y parcial, realizado por la política social derivada de la Ley 39 /2006, de I4 de diciembre, de Promoción de la Autonomía Personal y atención a las personas en situación de dependencia, se puede y debe destacar el enorme esfuerzo político realizado en España para implementar un sistema que, con sus luces y sus sombras, ha reconocido, reforzado y fortalecido el derecho subjetivo de las personas dependientes a ser atendido por los poderes públicos y administrativamente en el diseño e implementación del Sistema para la Autonomía y Atención a la Dependencia (SAAD). Esta apuesta pragmática ha permitido pasar, no de un plumazo, de un sistema familiarista a otro donde se contempla la responsabilidad pública en el cuidado y el reconocimiento del derecho social a ser cuidado. Una ambición, en el ámbito de la política social, y un pragmatismo que ha dejado sus frutos

Por ello, pese a lo ya visto y oído, hoy más que nunca, es necesario valorar y seguir valorando hasta qué punto la LAPAD ha modificado la concepción del gobierno de la política social a nivel de Estado y en los territorios concretos de las Comunidades autónomas, pues no se puede considerar que los avances del Estado de bienestar se produzcan únicamente en el marco jurídico sino que la asunción política de estos avances debe, por ejemplo, traducirse tanto en una oferta de prestaciones y servicios real, con suficiencia en la dotación de equipos, profesionales y plazas como en una relación administración - ciudadano /a no mediada por la complejidad y el letargo burocrático que dificulta, en gran medida, el simple acceso al derecho, sin hacer mención a la posibilidad real de ejercerlo después. 
Y ya para finalizar estas notas indicar que el futuro de la Ley de dependencia debe seguir ocupando un lugar preferente en la agenda política y en las preocupaciones de los ciudadanos ${ }^{40}$. En este momento histórico, no caben las vacilaciones ni tampoco las divagaciones en el empeño por fortalecer el bienestar de las personas dependientes.

\section{Bibliografía}

ARRIBA GONZALEZ, A. Y MORENO FUENTES, F. J. El tratamiento de la dependencia en los regímenes de bienestar europeos. Madrid, Ministerio de Sanidad, Política social e Igualdad, 2009.

CASADO, D. (dir.). Respuestas a la dependencia. Madrid, CCS, 2004.

CASADO, D. Y FANTOVA, F. (coords.). Perfeccionamiento de los Servicios Sociales. Informe con ocasión de la Ley sobre autonomía y dependencia. Madrid, Caritas Fundación FOESSA, 2007.

CERVERA, M. et al. Informe final del grupo de expertos para la evaluación del desarrollo y efectiva aplicación de la Ley $39 / 2006$ de 14 de diciembre de promoción de la autonomía personal $y$ atención a la dependencia. Ministerio de Sanidad y Política social, 2009 .

CHARro BAENA, A. Y SEMPERE NAVARRO, V. Comentario sistemático a la Ley de dependencia. Pamplona, Aranzadi, 2008.

RODRIGUEZ CABRERO, G. (dir.). Servicios Sociales y cohesión social. Madrid, Consejo Económico y Social, 20 II.

RODRIGUEZ CASTEDO, A. (dir.). Libro blanco de atención a las personas en situación de dependencia en España. Madrid, IMSERSO, 2004 .

ROLDAN GARCÍA, E. Y GARCÍA GIRÁLDEZ, T. Políticas de servicios sociales. Madrid, Síntesis.

SEMPERE NAVARRO, A. Comentario sistemático Ley de Dependencia: Ley 39/2006, de 14 de diciembre, de promoción de la autonomía personal y atención a las personas en situación de dependencia y normas autonómicas. Cizur Menor (Navarra), Thomson Aranzadi, 2008.

${ }^{40}$ Las propuestas legislativas del Gobierno de la nación auguran cambios profundos:

a) Real Decreto-ley $20 / 2012$, de I3 de julio, de medidas para garantizar la estabilidad presupuestaria y de fomento de la competitividad.

b) Resolución de I3 de julio de 20I2, de la Secretaría de Estado de Servicios Sociales e Igualdad, por la que se publica el Acuerdo del Consejo Territorial del Sistema para la Autonomía y Atención a la Dependencia para la mejora del sistema para la autonomía y atención a la dependencia. Publicado en Boletín Oficial del Estado, núm. I 85 de 3 de agosto de 20I2, páginas 55657 a 55674 (I8 págs.)

Cambios que han provocado reacciones públicas. Por ejemplo, la Defensora del Pueblo formula varias recomendaciones para mejorar la aplicación del RDL 20/2012 de medidas para garantizar la estabilidad presupuestaria y de fomento de la competitividad (nota de prensa I5 de octubre 20I2). Pide la revisión del sistema de afiliación, alta y cotización de los cuidadores de personas dependientes en el entorno familiar para evitar que queden fuera del Sistema de la Seguridad Social. 